\title{
ORGANIZATION AND EVALUATION OF A SUSTAINABLE ISLANDS NETWORK
}

\author{
K. HADJIBIROS ${ }^{1}$, M. ARAVANTINOU ${ }^{1} \&$ C. LASPIDOU ${ }^{1,2}$ \\ ${ }^{1}$ Department of Water Resources and Environmental Engineering, National Technical University of Athens, Greece. \\ ${ }^{2}$ Department of Civil Engineering, University of Thessaly, Greece.
}

\begin{abstract}
The DAPHNE network ( $\triangle \mathrm{A} \Phi \mathrm{NH}$, in Greek) has been developed for the Aegean islands with the objective to promote the sustainable development of a region that is ecologically sensitive and culturally rich. The basic tool employed is an evaluation-certification system that results in the yearly award of a sustainability badge for each qualified island. The evaluation process includes a series of activities, such as examining the condition in each island and detecting environmental pressures, defining widely acceptable sustainability priorities, and scheduling and assessing relevant actions. There are two basic axes in the evaluation methodology: island condition and program actions. Ten thematic sectors of sustainable development that are considered as including the maximum number of island condition and action cases have been selected. Sustainability assessment is done by assigning scores to a series of factors and by calculating a total score. Islands with yearly scores greater than or equal to a pre-defined minimum receive (or retain) the sustainability badge for that year.

Keywords: Greek islands, sustainability certification, sustainability criteria, sustainable development.
\end{abstract}

\section{INTRODUCTION}

Ecological 'insularity' and 'oceanicity' are general properties of islands and lead to an original combination of fragility and long-term persistence [1,2]. The Aegean archipelago has been a hot spot of high biodiversity and human civilization for thousands of years; it is an island system that has a triple bio-geographic influence, as it lies in the intersection of Europe, Asia and Africa. The natural beauty, climate, sea, architecture and the local hospitable character have all contributed to the tourist development [3] of the area in the last decades, with all the positive and negative consequences that follow: positive because of the economic benefits of tourism and negative because it created strong pressures on the environment and altered many of the authentic characteristics of the local communities. The sustainability proposal [4] could be the answer to the question 'development or environment?'; in the case of Aegean islands, it is necessary to protect this fragile but long-term persistent system. Sustainability is based on conservation of natural and cultural resources, while taking advantage of their qualities; it can combine high quality environment with a long-term perspective of tourism; it also combines innovative technologies with the creation of new opportunities for employment, business activity and social development.

Thirty-seven municipalities of thirty-one Aegean islands decided to establish a non-profit network agency, namely the DAPHNE ( $\triangle \mathrm{A} \Phi \mathrm{NH}$, in Greek) agency, a Greek acronym with its initials in Greek standing for Network of Sustainable Aegean Islands [5]. DAPHNE is a legal entity in the form of a municipalities network; according to the statute of the DAPHNE agency, its main objective is the promotion of sustainable development. The network organizes or promotes action programs in the islands for the environment, for economic development and employment. Specifically, it is directly connected to: (a) environmentally friendly development of the islands, (b) support of quality tourism and various forms of alternative tourism, (c) scheduling the construction of basic infrastructure works in the islands with a major interest in environmental protection, (d) regional development and decentralization and (e) support of sustainability terms in a local and global level. DAPHNE contributes to: the conservation and protection of the Aegean 
natural and cultural environment, which is a basic economic resource; strengthening the role of the island local community and government; formation of premises for healthy competition among those islands that aim at gaining certification for their quality businesses, especially in the area of tourism; creating a basis for communication and collaboration among the islands on subjects concerning environmental protection, cultural heritage and local development [6].

Basic tools for achieving these goals could be an evaluation system leading to a sustainability badge award, as well as the collaboration with other organizations, agencies and associations of municipalities in Greece and abroad and the participation to other geographically extensive networks.

\section{MATERIALS AND METHODS}

DAPHNE has developed an evaluation system that is applied annually and results in awarding (or renewing) the sustainability badge to islands that fulfill the agency requirements. The goal of the program is not to actually measure improvement in the environmental condition of each island, or to conduct a 'before' and 'after' comparison, but to give an incentive to the islands to take actions towards the goal of sustainability. There are two basic evaluation axes, each one with a corresponding weight coefficient:

- The island condition, with a weight coefficient of $30 \%$. The initial environmental condition of each island is examined through a rapid assessment, trying to identify possible environmental pressures.

- The sustainability actions that each island brings into effect under the program, with a weight coefficient of $60 \%$ for the actions value, plus a $10 \%$ bonus, awarded when the number of actions employed is the maximum, with the maximum number depending on the island's size; the program requires that the island submits a minimum of three to five (or two to three for very small islands) actions to qualify as a candidate for the badge. A realistic schedule of actions has to be defined and materialized by the island's municipality. The agency puts together a system of checks and keeps track of corresponding practices applied nationally and internationally.

Ten thematic sectors of sustainable development (Table 1) are taken into consideration to assess the island condition and action cases. Although it would be possible to include a limited number of thematic sectors, or sustainability parameters that would be easier to measure and monitor, it was decided, within the context of the program, to offer more options for improvement to the islands, even if the plethora of options makes evaluation more complex.

The condition is taken into consideration, so that the islands that have already achieved a degree of improvement will be rewarded; however, the main program objective remains the reward of positive efforts (conducive to sustainability) regardless of negative conditions in the island, therefore encouraging activities towards improvement. It should be noted that island's condition is only evaluated once, when the island applies for the sustainability badge for the first time. Further yearly environmental evaluations have not been conducted until now, as they are costly, time-consuming and difficult.

The island's municipality is responsible for reporting actions that will be taken in the context of the program for the evaluation year, which are later deemed by the evaluators as appropriate or not. Actions can be new, continuing or maintained; continuing actions are those that have been approved and scheduled by the program and need more than 1 year to be completed. Completed actions are maintained for as long as they are useful.

Conditions and actions are evaluated using certain criteria and indicators. For the island's condition, an examination of each one of the ten thematic sectors is conducted. Four condition indicators are 
Table 1: Thematic sectors of sustainable development used in the DAPHNE program.

\begin{tabular}{ll}
\hline Thematic sector no. & Thematic sector \\
\hline 1 & Water resources and wastewater \\
2 & Energy \\
3 & Municipal solid waste \\
4 & Tourism \\
5 & Natural environment \\
6 & Land use/planning \\
7 & Transportation \\
8 & Primary production (agriculture, animal raising, fisheries) \\
9 & Culture/education \\
10 & Social policy \\
\hline
\end{tabular}

used: (a) the number of sectors presenting high environmental quality, (b) the number of sectors presenting serious problems, (c) the number of these serious problems that are irreversible and (d) the number of sectors with positive interventions that have preceded the DAPHNE program. An advantage of such indicators is that they can be used even when detailed data on the condition of the islands are missing.

Regarding the actions that each island proposes and implements, examination takes place in two levels: on the one hand, the general value of each action is evaluated using criteria that take into account the degree of sustainability, the necessity, imperativeness and effectiveness, the positive influence and the absence of negative impact, the size, the cost and breadth of each action. On the other hand, the progress of implementing the action is evaluated with corresponding criteria that take into account how closely the schedule is followed, the execution of necessary supporting actions, the progress reassurance, the right direction and comprehension of the action and the implementation results.

Evaluation is conducted on an annual basis. All indicators are assigned a score and are used with their corresponding weights in a formula (eqn (1), presented in the next section), calculating the final score of each island for the specific year. Based on that score, a decision whether the island will receive or retain the sustainability badge is made by the network agency.

We start by the principle that a large number of actions is not necessary for each island, as this could compromise the quality and integrity of each action. An action with a very low score is not taken into account during the evaluation, so that it does not significantly reduce the island score, and so that islands are discouraged to take up actions that are insignificant and unworthy, only to increase the total number of actions taken. Besides, it is important to establish continuity for all actions that need to be continued and to maintain those actions that need maintenance.

Furthermore, the agency has supporting mechanisms that are responsible for the following:

- Collection of available data that initially describe the trends that prevail in each island examined and are relevant to the thematic sectors.

- Definition of the necessary prerequisites for the island's sustainable development, having participated in an information campaign and a dialog with the locals and local enforcement agencies of the island.

- Compilation of a schedule for the materialization of the suggested actions. This schedule forms the basis for watching the progress of each island as a member of the network. 


\section{RESULTS}

When an island is ready to be considered for a sustainability badge, it submits a series of proposed actions that concern some of the different thematic sectors. An evaluator visits the island, assesses each of the actions submitted by the island authorities for evaluation and fills out one action evaluation sheet for each action. The condition evaluation sheet is also filled out, based on the relevant report that had been compiled for the island. Such reports were prepared 3 years ago for 27 islands by a team of young researchers.

In the condition evaluation sheet, the four relevant condition indicators presented before are worded in such a way that a yes corresponds to each case that is positive for the environment. The score of the island's condition results from the number of yes's weighed by corresponding coefficients.

In Table 2, we present an example of an action evaluation sheet for the island of Milos referring to the construction of a wastewater treatment and water reclamation plant; this action obtained a high score. One can observe all criteria and sub-criteria, as well as the score assigned for each one (highest score is 100 and lowest is 0 ). Milos island submitted five actions in order to qualify for the sustainability badge. The same process is repeated for all actions for each island municipality that applies for the badge (first time, or renewal). All results are then compiled in the following equation that produces the overall score for the island and decide whether it qualifies for the badge:

$$
\mathrm{B}=0.30 * \mathrm{~K}+0.60 * \Delta+0.10 * \mathrm{~A}
$$

where $\mathrm{B}$ is the overall score, $\mathrm{K}$ is the condition score, $\Delta$ is the final actions score and $\mathrm{A}$ is the bonus score that is awarded when the number of actions employed is the maximum. Islands with overall yearly scores greater than or equal to $60 \%$ receive (or retain) the sustainability badge. In addition, the island with the highest score each year receives a monetary award offered by a sponsor.

Table 3 presents a list of all islands that have gone through the evaluation process with the DAPHNE program in 2009. While it is the first time for some islands, it is a badge renewal process for others. A list of actions taken by each island is shown in the table, as well as the corresponding average action score, the island condition score and the final overall score, which is calculated with eqn (1). During the evaluation step, an action evaluation sheet, such as that shown in Table 2, is completed for each action shown in Table 3, to get an action score. It should be noted that islands that are candidates for the badge go through a pre-evaluation step to ensure that the actions proposed are sufficient for the award. Therefore, all candidates that get to the evaluation process are, in principle, successful in getting the badge. This is done in order to protect elected officials that promote such efforts for their islands from being charged with a political failure, if actions taken are not sufficient for the sustainability badge.

Due to space limitation, detailed results from the program are not presented for the first 2 years of the program in Table 3, but are only summarized here. One sustainability badge for 2007 was awarded to Kea municipality (Kea island), thanks to the following actions that were enacted within the program: installation of a wastewater treatment plant, municipal solid waste recycling program, rebuilding/rehabilitation of pedestrian paths in the island and the organization of a fairytale festival. In 2008, six more members of the network were favorably evaluated and were awarded the sustainability badge: Heraklia community, municipalities of Ios (Ios island), Korthi (Andros island), Milos (Milos island), Moudros (Lemnos island), Poseidonia (Syros island). Also, Kea municipality was re-evaluated and retained its badge. In 2008, the highest score was accumulated by Milos island, which brought into effect the following actions: Installation and operation of a desalination plant with wind power and a central wastewater treatment plant with water reuse for irrigation, protection and augmentation of the endangered coastal plant species Pancratium maritimum, development of a city plan and completion of preparatory actions for the creation of a GeoPark. 
Table 2: Sample action evaluation sheet for Milos Island.

\begin{tabular}{|c|c|c|c|c|}
\hline \multicolumn{4}{|c|}{ ACTION EVALUATION SHEET } & \multirow[b]{2}{*}{ Category } \\
\hline Island & Year & Sector & Code & \\
\hline \multirow[t]{2}{*}{ Milos } & 2008 & Water resources & 020805 & 01 \\
\hline & & $\begin{array}{r}\text { Construction of centra } \\
\text { plant }\end{array}$ & $\begin{array}{l}\text { vater treatn } \\
\text { e-used for }\end{array}$ & vater reclamation \\
\hline
\end{tabular}

Criteria

Criteria Scoring Documentation

1. General value of the action

1.1. Importance/sustainability

1.1.1. Environmental-sustainable action

Innovative action with a very important environmental-sustainability dimension

1.1.2. Size - cost

Multiple-year action, first phase completed (completion and trial operation of the plant)

1.1.3. Extent of positive influence on other thematic sectors

Score

There is an important influence on tourism, and primary production

1.1.4. Absence of negative impacts

No negative impact has been identified so far

\subsection{Necessity}

1.2.1. Degree of imperativeness

There was wastewater run-off in streams, wastewater transport by trucks with intense odor problems, pollution or aquifer, need for irrigation water

1.2.2. Correlation with existent negative cases (from initial condition evaluation)

Discharge in sink-holes and streams, lack of irrigation water

2. Action materialization

2.1. Materialization progress

2.1.1. Degree of materialization - operation, observance of schedule

On-time completion of phase A; phases B and C to follow (pipeline, irrigation with an update in $1-2$ years)

2.1.2. Execution of necessary supporting actions

Network advancement and other actions

\subsubsection{Progress reassurance}

Possibly the private company will ensure that progress is made, otherwise the municipality will ensure the continuity of the works

\subsection{Direction}

2.2.1. Right direction of materialization and action comprehension

It has been constructed correctly and there is adequate briefing/information

2.2.2. Materialization consequence in relation to design. Complete 
Table 2: Continued

\subsection{Materialization results}

2.3.1. Quantitative and qualitative data of materialization results

The general picture is satisfactory, wastewater will inflow in 2 weeks, the technology has been tested in Kea island; It is too soon for measurements

2.3.2. Questionnaires, general public and target groups opinion polls

They do not exist at the present

Table 3: Data for islands that joined the DAPHNE program in 2009.

\begin{tabular}{|c|c|c|c|c|c|}
\hline Island & Action & $\begin{array}{l}\text { T.S. } \\
\mathrm{No}^{1}\end{array}$ & $\begin{array}{c}\mathrm{C}^{2} \\
\text { score } \\
(\mathrm{K})\end{array}$ & $\begin{array}{l}\text { A.A. } \\
\text { score } \\
(\Delta)\end{array}$ & $\begin{array}{l}\text { Overall } \\
\text { score } \\
\text { (B) }\end{array}$ \\
\hline \multirow{5}{*}{ Oia-Santorini island } & $\begin{array}{l}\text { Improved operation of desalination units } \\
\text { and water distribution network }\end{array}$ & 1 & \multirow{5}{*}{$56 \%$} & \multirow{5}{*}{$72.3 \%$} & \multirow{5}{*}{$70.2 \%$} \\
\hline & $\begin{array}{l}\text { Conducted city planning study for } \\
\text { Therasia community }\end{array}$ & 6 & & & \\
\hline & $\begin{array}{l}\text { Restored trails and small streets and } \\
\text { buried electrical cables }\end{array}$ & 9 & & & \\
\hline & $\begin{array}{l}\text { Switched to energy-saving light bulbs in } \\
\text { public buildings and made vehicles more } \\
\text { energy efficient }\end{array}$ & 2 & & & \\
\hline & $\begin{array}{l}\text { Conducted transportation study for Oia } \\
\text { community }\end{array}$ & 7 & & & \\
\hline \multirow{3}{*}{ Korthi-Andros island } & $\begin{array}{l}\text { Initiated municipal solid waste recycling } \\
\text { program }\end{array}$ & 3 & & & \multirow{3}{*}{$65.1 \%$} \\
\hline & $\begin{array}{l}\text { Completed construction works of } \\
\text { sewerage network and connected to } \\
\text { wastewater treatment plant }\end{array}$ & 1 & $62 \%$ & $77.5 \%$ & \\
\hline & $\begin{array}{l}\text { Initiated operation of Center for } \\
\text { Environmental Education }\end{array}$ & 9 & & & \\
\hline \multirow{3}{*}{ Ios island ${ }^{4}$} & Conducted city planning study & 6 & & & \multirow{3}{*}{$61.5 \%$} \\
\hline & $\begin{array}{l}\text { Featured historical heritage through } \\
\text { cultural monuments, restored one wind } \\
\text { mill and three trail parts. }\end{array}$ & 9 & $61 \%$ & $72.0 \%$ & \\
\hline & $\begin{array}{l}\text { Full-scale material recycling; landfilling } \\
\text { of only inert residues }\end{array}$ & 3 & & & \\
\hline \multirow{5}{*}{ Kea island ${ }^{4}$} & $\begin{array}{l}\text { Conservation of traditional forms of } \\
\text { primary production }\end{array}$ & 8 & \multirow{5}{*}{$53 \%$} & \multirow{5}{*}{$72.1 \%$} & \multirow{5}{*}{$69.2 \%$} \\
\hline & Municipal solid waste recycling & 3 & & & \\
\hline & Featured and restored network of trails & 9 & & & \\
\hline & Water and wastewater management & 1 & & & \\
\hline & Fairytale festival & 9 & & & \\
\hline
\end{tabular}


Table 3: Continued

\begin{tabular}{|c|c|c|c|c|c|}
\hline \multirow{5}{*}{ Amorgos island ${ }^{4}$} & Featured-restored agricultural heritage & 9 & \multirow{5}{*}{$55 \%$} & \multirow{5}{*}{$74.1 \%$} & \multirow{5}{*}{$71.0 \%$} \\
\hline & $\begin{array}{l}\text { Promotion of primary production sector } \\
\text { with the use of biological methods }\end{array}$ & 8 & & & \\
\hline & Restored illegal waste dump & 3 & & & \\
\hline & $\begin{array}{l}\text { Installed tertiary wastewater treatment } \\
\text { system }\end{array}$ & 1 & & & \\
\hline & $\begin{array}{l}\text { Established an integral municipal solid } \\
\text { waste management system }\end{array}$ & 3 & & & \\
\hline \multirow{5}{*}{ Milos island ${ }^{4}$} & $\begin{array}{l}\text { Addition of a wind-powered } \\
\text { desalination unit }\end{array}$ & 1 & \multirow{5}{*}{$56 \%$} & \multirow{5}{*}{$73.1 \%$} & \multirow{5}{*}{$70.7 \%$} \\
\hline & Municipal solid waste recycling & 3 & & & \\
\hline & $\begin{array}{l}\text { Initiated a program to promote and } \\
\text { protect unique island features that are } \\
\text { either natural or man-made }\end{array}$ & 9 & & & \\
\hline & $\begin{array}{l}\text { Completed construction of the water } \\
\text { distribution system }\end{array}$ & 1 & & & \\
\hline & $\begin{array}{l}\text { Operate wastewater treatment and } \\
\text { reclamation plant (water re-used } \\
\text { for irrigation) }\end{array}$ & 1 & & & \\
\hline \multirow{5}{*}{$\begin{array}{l}\text { Moudros Lemnos } \\
\text { island }^{4}\end{array}$} & Conducted city planning study & 6 & \multirow{5}{*}{$59 \%$} & \multirow{5}{*}{$70.6 \%$} & \multirow{5}{*}{$70.1 \%$} \\
\hline & $\begin{array}{l}\text { Installed web-based system for } \\
\text { the fast and convenient on-line } \\
\text { processing of citizen applications to } \\
\text { the municipality }\end{array}$ & 10 & & & \\
\hline & $\begin{array}{l}\text { Replacement/restoration of parts of water } \\
\text { distribution network }\end{array}$ & 1 & & & \\
\hline & $\begin{array}{l}\text { Construction/restoration of listed } \\
\text { building used as a primary school }\end{array}$ & 9 & & & \\
\hline & Production of potable water & 1 & & & \\
\hline \multirow{5}{*}{$\begin{array}{l}\text { Poseidonia Syros } \\
\text { island }^{4}\end{array}$} & $\begin{array}{l}\text { Domestic composting - branch } \\
\text { chipping - recycling }\end{array}$ & 3 & \multirow{5}{*}{$52 \%$} & \multirow{5}{*}{$79.9 \%$} & \multirow{5}{*}{$73.5 \%$} \\
\hline & $\begin{array}{l}\text { Landfill construction/recycling } \\
\text { system }\end{array}$ & 3 & & & \\
\hline & $\begin{array}{l}\text { Established drinking water production/ } \\
\text { disposal plant }\end{array}$ & 1 & & & \\
\hline & Conducted city planning study & 6 & & & \\
\hline & $\begin{array}{l}\text { Beaches made accessible to mobility } \\
\text { impaired persons }\end{array}$ & 10 & & & \\
\hline
\end{tabular}

${ }^{1}$ Thematic sector number relevant to each activity (as listed in Table 1).

${ }^{2}$ Island Condition Score.

${ }^{3}$ Average Score of all Actions.

${ }^{4}$ Sustainability badge renewal. 


\section{DISCUSSION AND CONCLUSIONS}

The evaluation system described herein is original and experimental and is adapted to the specific environmental, geomorphological and/or political conditions of each island [2]. It must be subject to extensive research and continuous improvement based on experience built and results obtained. Discussion and further thinking have taken place during the project implementation, concerning the respective value of actions in terms of whether they are new, continuing or maintained actions. More specifically, in case that continuing actions have been scheduled in the framework of the program and need more than 1 year to be completed, they might be scored similarly to new ones. On the other hand, maintained actions may be considered as less important, but this would create a risk of promoting mainly new actions, while increasing the tendency of abandoning old ones. Up to now, we have evaluated all actions on the same basis and criteria, since other options do not provide yet a safe and objective solution. Therefore, in order for an island to retain or increase the score that already has accumulated, it will have to promote new actions, while at the same time, it continues applying the old ones. The evaluation will be improved if a new assessment of the island's condition is made on a regular basis. The condition indicators could also be further discussed in terms of their need for experienced evaluators to make estimations due to the lack of regular data series for applying more precise evaluation parameters.

The program has been enforced for only 3 years now and has already been proved effective in providing the islands with the incentives, guidelines and a framework to operate within, in order to make possible the realization of efforts and actions towards a more sustainable way of development. The program will continue with the objective to get even more islands involved. Good communication with key people on the islands is required in order to motivate them and help them undertake their own initiatives [7]. Although the evaluation method could be improved in the future with more sophisticated indicators, it has been proved that it is objective enough to capture the real situation in the islands satisfactorily. Naturally, a network like DAPHNE requires funding for management, coordination and monitoring of island activities. Participating islands could provide such funding. The idea of rewarding the islands with the sustainability badge is an efficient incentive for motivating them, provided that it works objectively and the process is continuously monitored.

\section{REFERENCES}

[1] Cronk, Q.C.B., Islands: stability, diversity, conservation. Biodiversity and Conservation, 6, pp. 477-493, 1997. DOI:10.1023/A:1018372910025

[2] Mantoglou, A., Hadjibiros, K., Panagopoulos, P. \& Varveris, T., Sustainable development programme for the Greek islands. Proc. Int. Congr. PRELUDE Sustainable Development in the Islands and the Roles of Research and Higher Education, Rhodes, 1998.

[3] Karatzoglou, B. \& Spilanis, I., Sustainable tourism in Greek islands: the integration of activitybased environmental management with a destination environmental scorecard based on the adaptive resource management paradigm. Business Strategy and the Environment, 2009. DOI:10.1002/bse.627

[4] Briguglio, L., Archer, B. \& Jafari, J. (eds), Sustainable Tourism in Islands and Small States: Issues and Policies, London, Cassel, 1996.

[5] Efthimiopoulos, I. \& Hadjibiros, K., Sustainability and insularism: the case of the Aegean islands, The Ecogeography of the Mesogeios Sea, ed. M. Modinos, Stochastis/DIPE Athens, pp. 243-259, 2001 (in Greek).

[6] Hadjibiros, K. \& Kyritsis, E., Sustainable islands network: a perspective of sustainability or a dead end development. Proc. 7th Int. Conf. on Environmental Science and Technology, Vol. A, University of the Aegean: Syros, pp. 301-309, 2001.

[7] EEC. http://ec.europa.eu/regional_policy/, 2008. 